\title{
A Festschrift in honor of Emmanuël Sérusiaux, lichenologist and environmentalist
}

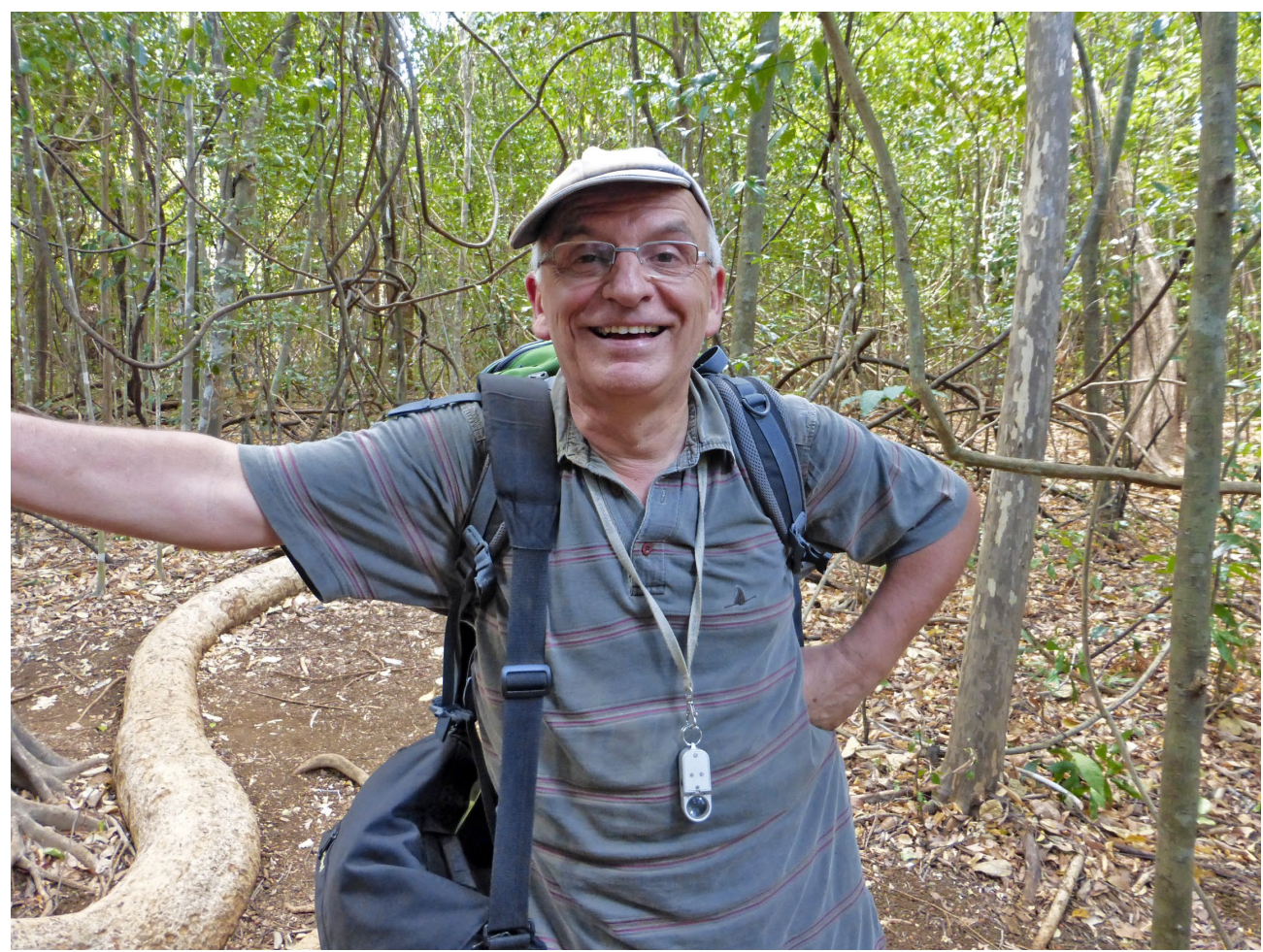

Professor Emmanuël Sérusiaux in Madagascar in 2014. Photograph by Damien Ertz

This special issue of Plant and Fungal Systematics is dedicated to Professor Emmanuël Sérusiaux on the occasion of his retirement. It presents 16 papers related to his scientific interests. Over the course of his distinguished career, Professor Sérusiaux has devoted his work to elucidating the systematics of lichen-forming fungi, as well as conservation biology and teaching. Emmanuël was born on October $3^{\text {rd }}$, 1953, in Dinant, Belgium. He obtained his 'license' (master's degree) in botany in 1975 and his doctorate of botanical sciences in 1982 under the supervision of Professor Jacques Lambinon at the University of Liège, Belgium. Emmanuël pursued his entire academic career at the University of Liège, and took three sabbatical leaves to dedicate his time to political and environmental activities. Emmanuël retired in October 2019, but we feel certain that he will continue contributing to progress in lichenology for years to come.

Recognizing Professor Emmanuël Sérusiaux's significant contribution to the field of lichenology, and in particular to the systematics of foliicolous lichens, Peltigerales and the flora of tropical Africa, it is our honor to dedicate this issue to him in celebration of his accomplishments, and to wish him well in his future endeavors. We thank the authors for their contributions to this issue, which is published to express our heartfelt appreciation of Emmanuël's lifework.

Nicolas Magain

Institut de Botanique, Université de Liège, Liège, Belgium

Damien Ertz

Meise Botanic Garden, Meise, Belgium

Bernard Goffinet

Department of Ecology and Evolutionary Biology, University of Connecticut, Storrs CT, USA

Paul Diederich

Musée national d'histoire naturelle, Luxembourg, Luxembourg Adam Flakus

W. Szafer Institute of Botany, Polish Academy of Sciences, Kraków, Poland

Jolanta Miadlikowska

Department of Biology, Duke University, Durham NC, USA 